\title{
Cost and pollution by the use of xylene in cervical cytology in
}

\section{four Peruvian hospitals [version 1; peer review: 1 approved}

\section{with reservations, 1 not approved]}

\author{
Jeel Moya-Salazar1,2, Richard Salazar-Hernández², Victor Rojas-Zumaran², \\ Gloria Cruz-Gonzales², Hans Contreras-Pulache(iD)1
}

\footnotetext{
${ }^{1}$ South America Center for Education and Research in Public Health, Universidad Norbert Wiener, Lima, +51, Peru

2Department of Pathology, Hospital Nacional Docente Madre Niño San Bartolomé, Lima, +51, Peru

${ }^{3}$ Department of Pathology, Hospital Nacional Guillermo Almenara Irigoyen, Lima, +51, Peru
}

V1 First published: 25 Aug 2021, 10:848

https://doi.org/10.12688/f1000research.52769.1

Second version: 21 Apr 2022, 10:848

https://doi.org/10.12688/f1000research.52769.2

Latest published: 08 Jun 2022, 10:848

https://doi.org/10.12688/f1000research.52769.3

\section{Abstract}

Background: Cytological samples are cleared with xylene in two or three baths during a Pap test, however, this solvent has a high degree of toxicity, and being a controlled reagent infers high costs for its purchase and implications for environmental pollution. We estimated the impact of xylene during the Pap test in terms of the number of liters and cost of two baths of xylene, and also estimated the impact with three baths

Methods: This cross-sectional study was carried out in four hospitals of EsSalud in Peru in two stages. First, the analysis of the impact due to the use of two baths of xylene was conducted during the period 2015-2019, and second, the estimates were calculated based on the assumption of three baths of xylene for the years 2020-2025. The assumption was based on the recommendations of the 2018 EsSalud cytology guideline. The monthly amount of xylene was $~ 10$ liters per bath/month and the cost per liter was estimated at 8.13 USD ( 27 soles).

Results: For the staining of 594,898 cytology tests, 7,848 liters of xylene were necessary, resulting in a cost of 60,861 USD $(202,068$ soles) during the period 2015-2019. The estimates showed a maximum assumption of 9,483 liters and 77,110 USD ( 256,040 soles) for the use of three baths of xylene in the four EsSalud hospitals ( $p=$ 0.0025 ) during the period 2020-2025.

Conclusions: We determined that there was a high economic impact of using xylene with two baths from 2015 to 2019 and a dramatic increase in costs with the possible use of three baths of xylene in the Pap test for the following five years.

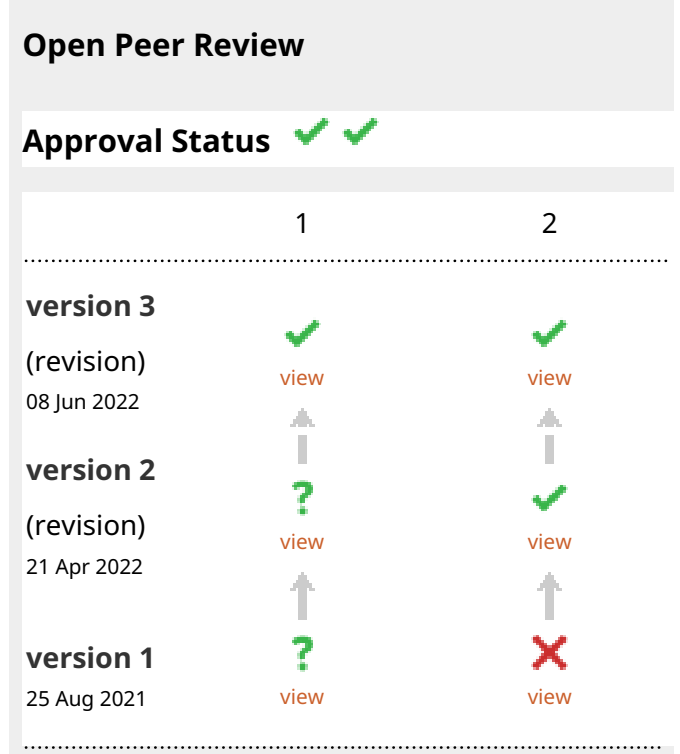

1. Nasar Yousuf Alwahaibi (iD), Sultan Qaboos University, Muscat, Oman

2. Alexandre Rieger (iD, University of Santa Cruz do Sul (UNISC), Santa Cruz do Sul, Brazil Alessandra Koehler, Federal University of Rio Grande do Sul (UFRGS), Porto Alegre, Brazil

Any reports and responses or comments on the article can be found at the end of the article. 
Keywords

xylene, polycyclic aromatic hydrocarbon, cervical cancer, Pap test, pollution, Peru

Corresponding authors: Jeel Moya-Salazar (jeel.moya@uweiner.edu.pe), Hans Contreras-Pulache (hans.contreras@uwiener.edu.pe)

Author roles: Moya-Salazar J: Conceptualization, Data Curation, Formal Analysis, Investigation, Visualization, Writing - Original Draft Preparation, Writing - Review \& Editing; Salazar-Hernández R: Conceptualization, Data Curation, Writing - Original Draft Preparation, Writing - Review \& Editing; Rojas-Zumaran V: Conceptualization, Writing - Original Draft Preparation, Writing - Review \& Editing; CruzGonzales G: Data Curation, Writing - Original Draft Preparation, Writing - Review \& Editing; Contreras-Pulache H: Conceptualization, Formal Analysis, Project Administration, Writing - Original Draft Preparation, Writing - Review \& Editing

Competing interests: Jeel Moya-Salazar and Victor Rojas-Zumaran are the developers of the Eco-Pap, this coloration is currently pursuing patent. The other authors do not declare other competing interests.

Grant information: The author(s) declared that no grants were involved in supporting this work.

Copyright: @ 2021 Moya-Salazar J et al. This is an open access article distributed under the terms of the Creative Commons Attribution License, which permits unrestricted use, distribution, and reproduction in any medium, provided the original work is properly cited.

How to cite this article: Moya-Salazar J, Salazar-Hernández R, Rojas-Zumaran V et al. Cost and pollution by the use of xylene in cervical cytology in four Peruvian hospitals [version 1; peer review: 1 approved with reservations, 1 not approved] F1000Research 2021, 10:848 https://doi.org/10.12688/f1000research.52769.1

First published: 25 Aug 2021, 10:848 https://doi.org/10.12688/f1000research.52769.1 


\section{Introduction}

Xylene $\left(\mathrm{C}_{6} \mathrm{H}_{4}\left(\mathrm{CH}_{3}\right)_{2}\right)$ is a polycyclic aromatic hydrocarbon (PAHs) part of the aromatic BTXs (benzene, toluene, and xylenes) obtained from petroleum, from the dry distillation of wood, and from coke gases. Xylene can have one of the three isomers of dimethylbenzene or a combination thereof, which are used as solvents (in fuel formulations, and glue in plastic model kits etc.). ${ }^{1}$ In medical practice, xylene is used in cellular clarification in the final phase of tissue processing. 2,3

Since George Papanicolaou's research began in 1914 at Weill Cornell University, these PAHs have been used as part of the Papanicolaou (Pap) stain to clear cells at the end (clearing) of the process. ${ }^{4}$ The preliminary Pap protocol as well as the modifications that he made in 1953 and 1959 indicates the use of three xylene baths $\left(\sim 350 \mathrm{ml}\right.$ each) during the process. ${ }^{5}$ These protocols, and several modifications ${ }^{6,7}$ suggest the use of one or three xylene baths, causing high exposure to workers (as several hospitals do not have adequate protection barriers), bioaccumulation, and environmental pollution (due to the incorrect handling of these wastes). ${ }^{8}$

Even though there are techniques for the biodegradation of xylene such as the use of iron and manganese from underground aquifers, the biofiltration of xylene by microorganisms adhered to a Nylon support, ${ }^{9,10}$ and modifications of the Pap stain that avoid the use of xylene (and other pollutants), $8,11,12$ laboratories in many countries continue using xylene as a cellular clarifier in two or three baths during the process. According to the standardized operating procedures of each cytology laboratory, these baths are replaced every thousand slides or once a week. ${ }^{12}$

In this study, we aimed to estimate the impact of xylene during the Pap test in terms of number of liters and costs for two baths of xylene, and also estimated the impact with three baths for the next five years (2020-2025) following the 2018 Peruvian Social Security cytology guideline.

\section{Methods}

Study design and hospitals

This was a retrospective longitudinal study that used a model for estimating xylene prices and quantities through logistic regression and the Bayes test. This study was approved by the Ethics Committee of Universidad Norbert Wiener (UNW$\mathrm{N}^{\circ}$ 072-2020). The study was conducted in two stages with data on costs and quantities (in liters) of xylene used in cytology over a five-year period (2015-2019) in four hospitals (Figure 1) of Social Security (EsSalud) of Peru. ${ }^{13}$

o Hospital Nacional Guillermo Almenara Irigoyen (HNGAI)

o Hospital Nacional Edgardo Rebagliati Martins (HNERM)

o Hospital Nacional Alberto Sabogal Sologuren (HNASS)

o Hospital Nacional de Emergencias Grau (HNEG)

The EsSalud cytology guide, Chapter 9. Cervical cytology procedures in the laboratory: Section 9.5.1. Manual staining describes the process, which includes three xylene baths (10 minutes each) at the end of the staining procedure (https:// ww1.essalud.gob.pe/compendio/pdf/0000003706_pdf.pdf). ${ }^{14,15}$

First and second stage

In the first stage we collected the data on xylene use for the period 2015-2019 in the four hospitals. ${ }^{13}$ The amount of xylene used for exfoliative cytology was $\sim 10$ liters per bath/month (with two xylene-baths), ${ }^{14,15}$ and the global cost (EsSalud) per liter of xylene was 8.13 US dollars (USD) per liter (27 soles). We estimated the number of cytology tests and the amount of xylene per year used as part of the routine Pap test, which follows the second protocol of Papanicolaou. ${ }^{4}$

For the second stage, we followed the recommendations of the 2018 EsSalud cytology guidelines ${ }^{14,15}$ that establishes the addition of a third xylene bath during Papanicolaou staining. We considered the use of three xylene baths for each cervical smear, estimating the monthly usage in each hospital. As in the previous stage, the cost of xylene was estimated.

Cost analysis and pollution impact

We used the direct costs of purchasing xylene without considering the indirect costs of processing, logistics management and usage (man-hours) during the Pap test. The cost of one liter of xylene was determined according to the contract between the manufacturer and EsSalud, which is a standardized contract for all hospitals in Lima. 


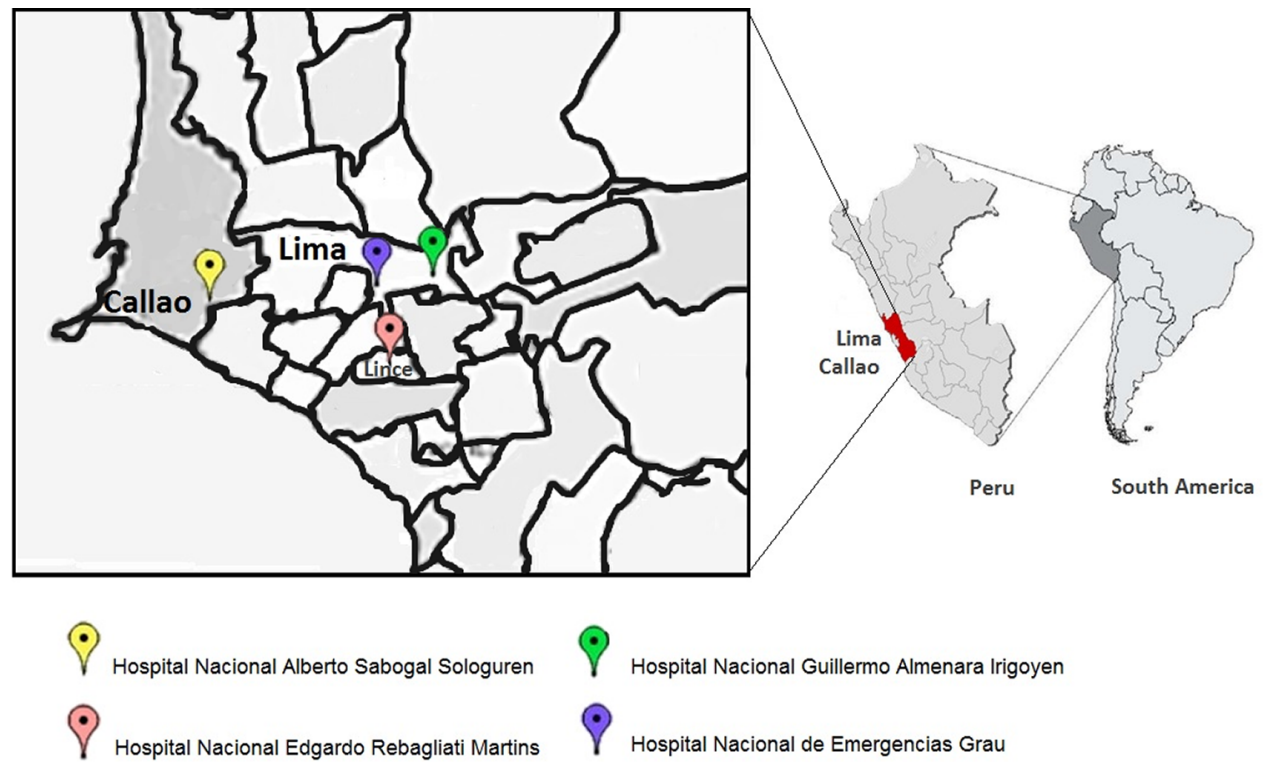

Figure 1. Location of the four EsSalud hospitals included in the study. Hospital Nacional Guillermo Almenara Irigoyen, Hospital Nacional Edgardo Rebagliati Martins, and Hospital Nacional de Emergencias Grau in Lima, and the Hospital Nacional Alberto Sabogal Sologuren in Callao province. Maps by @Jeel Moya-Salazar.
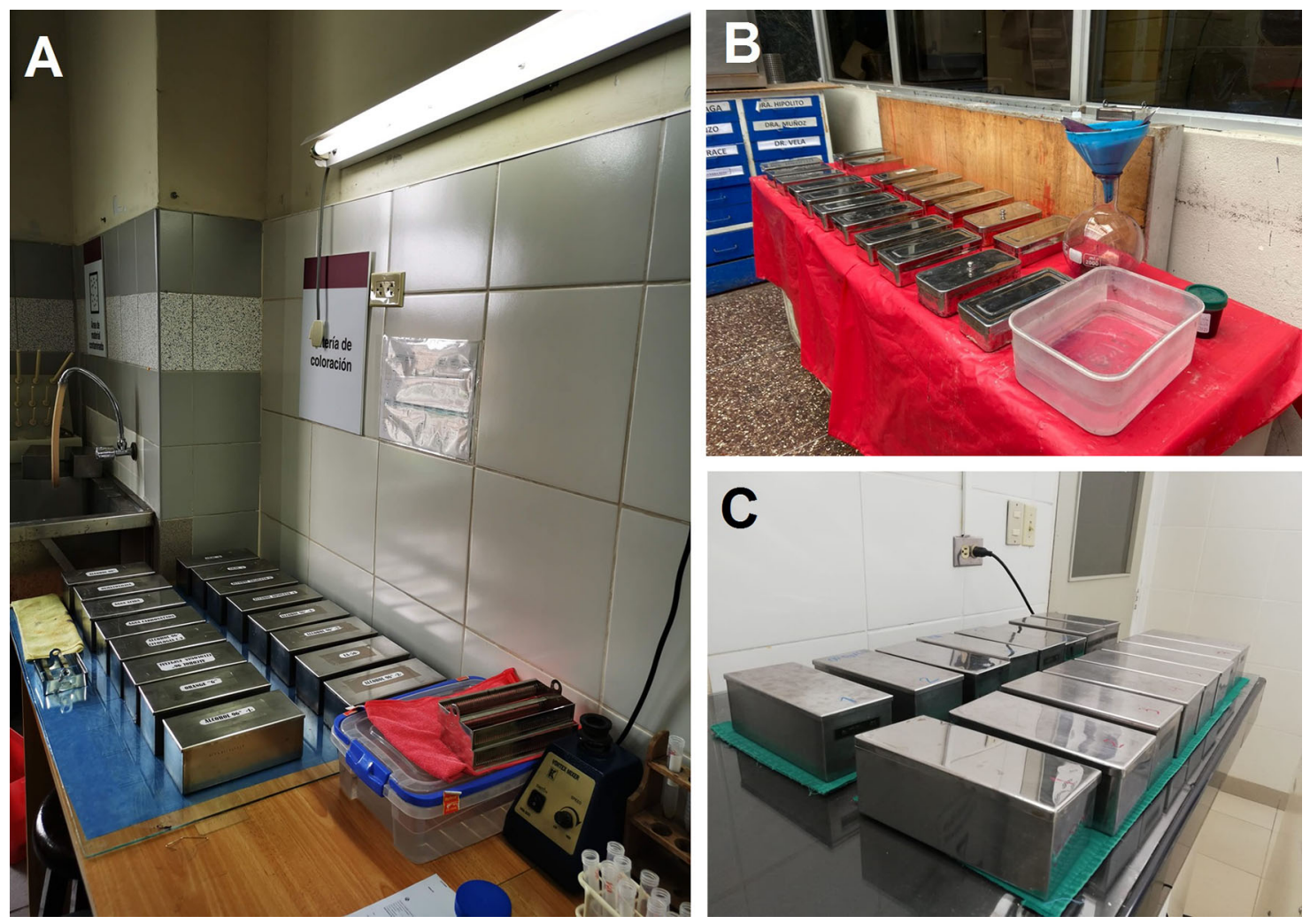

Figure 2. Biosafety conditions in cytology laboratories. (A) Guillermo Almenara Irigoyen National Hospital, (B) Hospital Nacional de Emergencias Grau, (C) Edgardo Rebagliati Martins National Hospital. Note that all staining centers are manual and are exempt from basic protection barriers such as the laminar flow chamber and air filtration systems.

Hence, we estimate the impact of pollution of xylene, initially by the amount of xylene used by the workers who were exposed daily to xylene under the biosafety conditions available in each hospital (Figure 2). Then, we estimated the pollution load based on the bioaccumulation of xylene during use, because the waste collection cycle is once every two months (hospital accumulation process). The quantity of liters and the costs (in USD) for xylene were estimated only for the Pap tests (we exclude the amount of xylene used in histology). 
In this sense, the monthly amount of xylene used in each hospital was estimated to establish the annual and the total cost (in liters). In the second stage, these costs and contamination estimates were made for the next five years (2020-2025) under the same parameters. The maximum and minimum amounts of xylene per year were used to estimate the costs and future quantities of xylene.

\section{Statistical analysis}

Statistical analysis was performed with descriptive statistics and frequency measures. To estimate the cost, directly purchased xylene was used, with an estimated price of USD 8.13 (27 soles) per liter. In order to assess the impact of contamination (two baths for cytological clearance), the annual reagent usage and the annual xylene bioaccumulation rate of four hospitals in Lima were considered. To estimate the impact of pollution and direct costs (between 2020-2025), of using three xylene baths, multiple logistic regression with Bayesian analysis was used, with a p-value $<0.05$ and a $95 \%$ confidence interval (CI) as significant. We used IBM Statistical Package for the Social Sciences (SPSS) v25.0 (Armork, US) for Linux for all data analysis.

\section{Results}

We included 131,456 cytology tests in the HNGAI, 254,106 in the HNERM, 110,858 in the HNASS, and 98,478 in the HNEG. The use of xylene during for the HNGAI, HNERM, HNASS and HNEG was 2,369, 2,299, 1,637, and 1,179 liters, respectively. Overall, a total of 7,484 liters of xylene were used for Pap stains in four EsSalud hospitals during a five-year period in Lima, Peru (Table 1). The mean rate of xylene use was $473.8 \pm 88.1$ liters (95\%CI 396.5 to 551.1) for

Table 1. Use of xylene and costs in four EsSalud hospitals. These data were estimated according to the amount of annual Pap tests during 2015-2019.

\begin{tabular}{|c|c|c|c|c|}
\hline Hospital & Year & Xylene (liters) & Cost (USD) & Cost (Soles) \\
\hline \multirow[t]{6}{*}{ HNGAI } & 2015 & 505 & 4106 & 13635 \\
\hline & 2016 & 504 & 4098 & 13608 \\
\hline & 2017 & 446 & 3627 & 12042 \\
\hline & 2018 & 575 & 4676 & 15525 \\
\hline & 2019 & 339 & 2756 & 9153 \\
\hline & TOTAL & 2369 & 19265 & 63963 \\
\hline \multirow[t]{6}{*}{ HNERM } & 2015 & 469 & 3814 & 12663 \\
\hline & 2016 & 562 & 4570 & 15174 \\
\hline & 2017 & 444 & 3610 & 11988 \\
\hline & 2018 & 392 & 3187 & 10584 \\
\hline & 2019 & 432 & 3513 & 11664 \\
\hline & TOTAL & 2299 & 18696 & 62073 \\
\hline \multirow[t]{6}{*}{ HNASS } & 2015 & 187 & 1520 & 5049 \\
\hline & 2016 & 544 & 4424 & 14688 \\
\hline & 2017 & 240 & 1951 & 6480 \\
\hline & 2018 & 330 & 2683 & 8910 \\
\hline & 2019 & 336 & 2732 & 9072 \\
\hline & TOTAL & 1637 & 13312 & 44199 \\
\hline \multirow[t]{6}{*}{ HNEG } & 2015 & 175 & 1423 & 4725 \\
\hline & 2016 & 350 & 2846 & 9450 \\
\hline & 2017 & 180 & 1463 & 4860 \\
\hline & 2018 & 114 & 927 & 3078 \\
\hline & 2019 & 360 & 2927 & 9720 \\
\hline & TOTAL & 1179 & 9588 & 31833 \\
\hline
\end{tabular}

Abbreviations: HNGAI: Hospital Nacional Guillermo Almenara Irigoyen, HNERM: Hospital Nacional Edgardo Rebagliati Martins, HNASS: Hospital Nacional Alberto Sabogal Sologuren, HNEG: Hospital Nacional de Emergencias Grau. Costs: 8.13 US dollars (USD) per liter (27 soles). 
HNGAI, $459.8 \pm 63.5$ liters (95\%CI 404.1 to 515.5) for HNERM, $327.4 \pm 136.3$ liters (95\%CI 207.9 to 446.9) for the HNASS, and $235.8 \pm 111.9$ liters (95\% CI 137.7 to 333.9) for the HNEG (Figure 3). Using this amount of xylene in four hospitals resulted in a cost of USD 60,853 (202,068 soles).

When estimating future costs for the five-year period from 2020 to 2025, the biggest assumption is that the use of three xylene baths in four hospitals is estimated at 9,483 liters and 77,110 USD (256040 soles). The lowest assumption for the use of three xylene baths in the next five years is estimated to be 5,485 liters and 44,590 USD $(148,080$ soles $)(p=0.0025)$ (Table 2). For HNGAI, HNERM, HNASS and HNEG, the maximum volume of the three xylene baths used is 561.9, 523.3, 463.7 and 347.7 liters, respectively. For HNGAI, HNERM, HNASS and HNEG, the minimum volume of the three xylene baths used is $385.7,396.3,191.1,123.9$ liters, respectively.

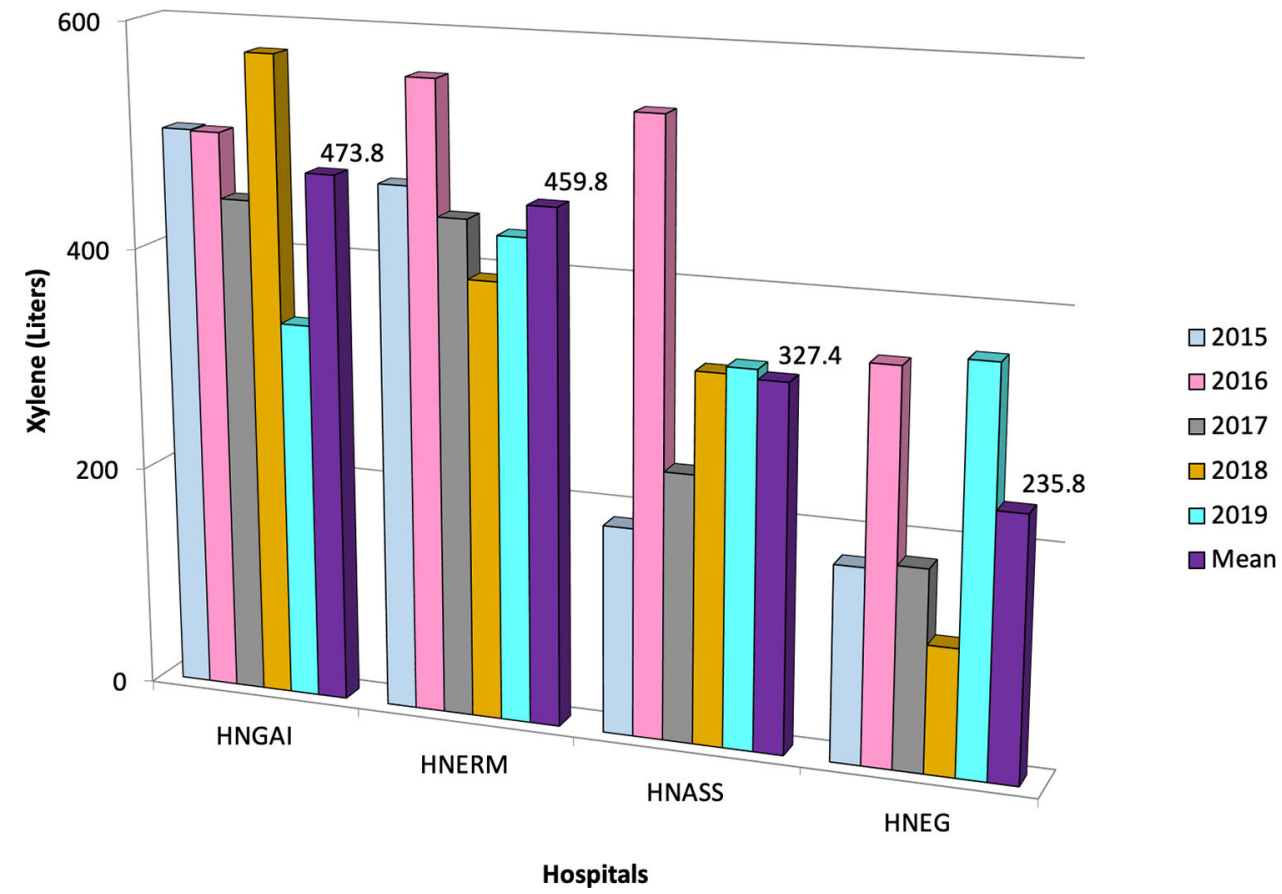

Figure 3. Amount of xylene used during Pap test in four Peruvian hospitals. Within the study period, the mean xylene used is shown for each year according to color. HNGAI: Hospital Nacional Guillermo Almenara Irigoyen, HNERM: Hospital Nacional Edgardo Rebagliati Martins, HNEG: Hospital Nacional de Emergencias Grau, HNASS: Hospital Nacional Alberto Sabogal Sologuren in Callao province.

Table 2. Quantity and, maximum and minimum costs and liters of xylene. We describe the quantities and, maximum and minimum costs estimated in this study at four EsSalud hospitals during 2015-2019 in Lima, Peru.

\begin{tabular}{|l|l|l|l|l|}
\hline Hospital & Assumptions & Xylene (liters) & Cost (USD) & Cost (Soles) \\
\hline HNGAI & Maximum & 2809.5 & 22845 & 75855 \\
\hline & Mínimum & 1928.5 & 15680 & 52070 \\
\hline HNERM & Maximum & 2616.5 & 21275 & 70645 \\
\hline HNASS & Mínimum & 1981.5 & 16110 & 53500 \\
\hline & Maximum & 2318.5 & 18855 & 62600 \\
\hline HNEG & Mínimum & 955.5 & 7765 & 25785 \\
\hline & Maximum & 1738.5 & 14135 & 46940 \\
\hline
\end{tabular}

Abbreviations: HNGAI: Hospital Nacional Guillermo Almenara Irigoyen, HNERM: Hospital Nacional Edgardo Rebagliati Martins, HNASS: Hospital Nacional Alberto Sabogal Sologuren, HNEG: Hospital Nacional de Emergencias Grau. Costs: 8.13 US dollars (USD) per liter (27 soles). 
A

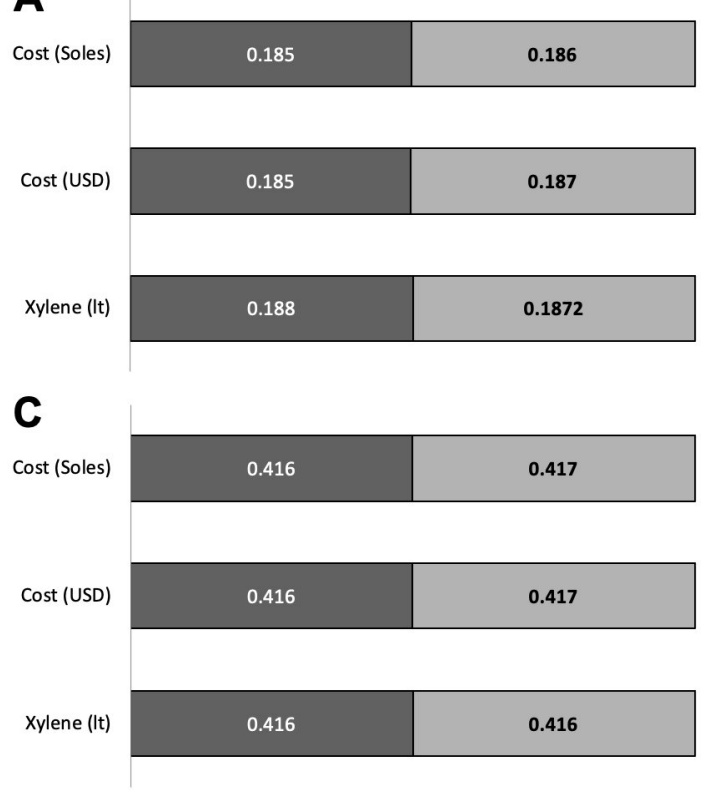

B

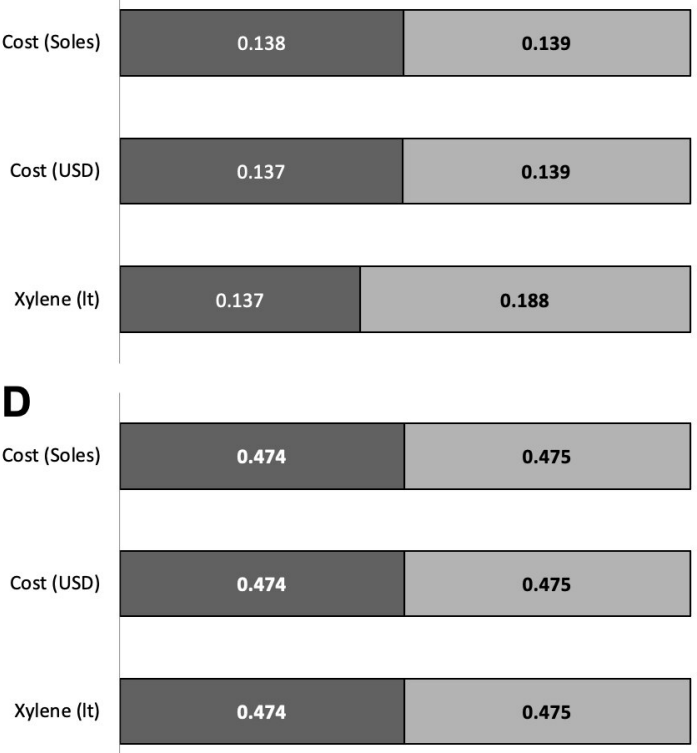

口Increase $\square$ Reduction

Figure 4. Increase or reduction (in liters and costs) of xylene in four EsSalud hospitals with the use of three xylene-baths in Pap staining. A. Hospital Nacional Guillermo Almenara Irigoyen, B. Hospital Nacional Edgardo Rebagliati Martins, C. Hospital Nacional Alberto Sabogal Sologuren, D. Hospital Nacional de Emergencias Grau. The increase indicates the maximum percentage of increase in the 2020-2025 periods in liters and costs of xylene. The reduction indicates the minimum percentage of reduction in the five-year period 2020-2025 in liters and costs of xylene.

These estimates of future costs showed increases and decreases according to the hospitals (Figure 4). In the four hospitals, the liter and cost of xylene increased by $30.4 \%$ and $30.3 \%$ USD on average, respectively. The average reduction in the cost and liters of xylene was $25.3 \%$ liters and $24.3 \%$ USD, respectively. A difference was determined between the increases in xylene use among EsSalud hospitals $(\mathrm{p}=0.0001)$.

\section{Discussion}

We determined that xylene had a high impact during the Pap test with two baths in four EsSalud hospitals, and a dramatic increase in costs and xylene contamination in the next five years (2020-2025) with the use of three xylene baths on the Pap smear according to the recommendations of the 2018 EsSalud cytology guidelines.

In the environment, xylene can cause air pollution due to the production of toxic gases (when it is thermally decomposed), polluting water, soil, and subsoil. ${ }^{16}$ Inhalation of xylene can irritate the mucous membranes of the nose and throat, and high concentrations can cause nausea, vomiting, headache, respiratory failure, cough, heart abnormalities, proteinuria, and hematuria. ${ }^{17}$ Cancer, leukemia, brain tumors and tissue changes (pulmonary long-term exposure and long-term high concentration) are also related to xylene contamination. ${ }^{18,19}$ Other effects include fetal kidney disease, infertility and miscarriage in children whose mothers have been in contact with xylene for a long time. ${ }^{20}$

Our estimates of xylene use in hospitals indicate that 594,898 cervical smears analyzed by Pap staining use $>7,000$ liters of xylene every five years. The same estimation of the use and contamination by xylene can be applied in other realities such as the 243,374 smears of the Hospital Nacional Docente Madre Niño San Bartolomé in Lima during two periods [118,016 for the conventional Pap staining (2011-2013 years) and 125,358 for the prolonged Pap staining (20132014 years)], ${ }^{11,21}$ to the 3,276,045 cervical smears of the Instituto Mexicano del Seguro Social in Mexico, ${ }^{22}$ and in the 60 million cervical smears performed annually in the United States. ${ }^{23}$ We can infer that in every country, cervical cancer screening will involve a large amount of xylene, which will threaten the health of laboratory workers and global environmental health.

Implementing a third xylene bath to the Pap test would undoubtedly have even more counterproductive results. As our findings indicate, there will be an increase in the overall costs of the tests (77,110 USD), the time to stain each sample, and the daily exposure of workers to higher amounts of xylene ( 9,483 liters). A previous study demonstrated that 37 national guidelines on prevention measures for the use of xylene in South American cytology laboratories were of little 
importance. ${ }^{24}$ In this sense, under the actual conditions of cytological screening in low-and-middle-income countries, adding an additional xylene bath to the Pap stain is unsustainable and therefore should not be considered.

Currently, there are xylene substitutes that allow diagnostic activities to be carried out in the pathology laboratory in a less toxic and eco-friendly environment. These substitutes are mainly the solution of Neo-Clear (Merck, Darmstadt, Germany), Pathoclear (Biopack, Buenos Aires, Argentina), Master clear (American MasterTech Scientific, CA, USA), UltraClear $^{\mathrm{TM}}$ (Avantor's JT Baker, Deventer, Netherlands), Shandon ${ }^{\mathrm{TM}}$ (Thermo Scientific, Walthman, MA, USA), and Ottix Plus (DiapathS.pA, Martinengo, Italy), which have shown different degrees of performance and health risks. ${ }^{25-27}$ Regardless of the opportunities these surrogates offer, they come with costs for Pap processing that many cytology labs cannot afford. In view of this, Eco-Pap (patent application pending) brings an alternative to ecological staining, which can reduce the number of reagents, staining time and cost without reducing test performance. ${ }^{8,12}$

On the other hand, our estimated analysis model for three xylene baths shows that the cost of the Pap stain and the liters of xylene solvent are reduced. However, this assumption could not be further from reality, given that exfoliative cytology has a new stage. ${ }^{28}$ This fact is partly due to the co-testing in which the Human Papilomavirus test and cytology are used as a strategy with better performance and diagnostic accuracy. ${ }^{29}$ It is also because many countries, mainly low- and middleincome countries, have strategies based on exfoliative cytology due to the benefits that this technique offers and for the economic limitations that these countries face. ${ }^{30,31}$

Another component that distances this assumption of reducing quantities and costs of xylene from reality is undoubtedly the alarming increase in the incidence and mortality from cervical cancer between 2012 and 2018 according to the International Agency for Research on Cancer (IARC) from 527,624 and 569,847 cases for the former, and from 265,672 to 311,365 cases for the second. ${ }^{32}$

In this sense, the use of cytology as a cervical cancer strategy will continue to develop and grow around the plausibility of other techniques such as molecular biology. Therefore, if a xylene bath is added to the Pap test, the amount and cost of xylene in Peru's EsSalud Hospitals will increase by an average of $16.6 \%$ in the next five years.

This study had limitations. 1) The analysis was conducted in four EsSalud hospitals in Lima, however, there are other hospitals that have not been included. Further studies that include other Social Security hospitals are needed; and 2) The analysis evaluated the xylene used in the Pap tests; however, it is necessary to evaluate its impact on histopathology.

\section{Conclusions}

We demonstrated a high economic impact of xylene during the Pap test with two xylene baths in four EsSalud hospitals, in Lima, Peru. Our three-bath estimates for 2020-2025 indicate that the economic growth of xylene use is significant, which is why the 2018 EsSalud cytology guidelines are not applicable.

Nowadays, there are some alternative methods that can make Pap smears free of xylene during the clearing process, thereby becoming ecofriendly, which is beneficial to occupational health and global environmental health.

\section{Data availability}

Underlying data

Figshare: 'Cost and pollution by the use of xylene in cervical cytology in four Peruvian hospitals',

https://doi.org/10.6084/m9.figshare.14615508.v1 $1^{13}$

This project contains the following underlying data:

- Table 1. Xylene database used in EsSalud hospitals 2015-19

Figshare: 'Cost and pollution by the use of xylene in cervical cytology in four Peruvian hospitals', https://doi. org/10.6084/m9.figshare.15048903.v1. ${ }^{14}$

This project contains the following underlying data:

\section{- 2018 EsSalud Cytology Guideline - Chapter 9 (English translation)}

Data are available under the terms of the Creative Commons Attribution 4.0 International license (CC-BY-4.0) 
1. Department of Health and Human Services public health service: Agency for Toxic Substance and Disease Registry. Toxicological profile for Xylene. Atlanta: ASTDR, CDC; 2007.

2. Culling CFA: Handbook of Histopathological and Histochemical Techniques. 3rd ed. London: Butterworth; 1974.

3. Prophet EB, Mills B, Sobin LH: Armed Forces Institute of Pathology Laboratory Methods in Histotechnology. Washington, D.C.: American Registry of Pathology Press; 1992.

4. Papanicolaou GN: A new procedure for staining vaginal smears. Science. 1942; 95(2469): 438-439. PubMed Abstract | Publisher Full Text

5. Chantziantoniou N, Donnelly AD, Mukherjee $M$, et al.: Inception and Development of the Papanicolaou Stain Method. Acta Cytol. 2017; 61(4-5): 266-280. PubMed Abstract | Publisher Full Text

6. Shinde PB, Pandit AA: Application of modified ultrafast Papanicolaou stain in cytology of various organs. Diagn Cytopathol. 2006; 34(2): 135-139. PubMed Abstract | Publisher Full Text

7. Gupta S, Chachra KL, Bhadola P, et al.: Modified Papanicolaou staining protocol with minimum alcohol use: a cost-cutting measure for resource-limited settings. Cytopathology. 2010; 21(4): 229-233.

PubMed Abstract | Publisher Full Text

8. Moya-Salazar J, Rojas-Zumaran V: Eco-Pap: an ecological Papanicolaou stain for sustainable cervical cancer diagnosis. Acta Cytol. 2019; 63(1): 35-43.

PubMed Abstract | Publisher Full Text

9. Villatoro-Monzón WR, Mesta-Howard AM, Razo-Flores E: Anaerobic biodegradation of BTX using Mn (IV) and $\mathrm{Fe}$ (III) as alternative electron acceptors. Water Sci Technol. 2003; 48(6): 125-131. PubMed Abstract

10. Ortega-González DK, Zaragoza D, Aguirre-Garrido J, et al.: Degradation of benzene, toluene, and xylene isomers by a bacterial consortium obtained from rhizosphere soil of Cyperus sp. grown in a petroleum-contaminated area. Folia Microbiol (Praha). 2013; 58(6): 569-577. PubMed Abstract | Publisher Full Text

11. Moya-Salazar J, Rojas-Zumaran V: Validation of the modification of the prolonged Papanicolaou stain for the diagnosis of cervical cancer. Acta Cytol. 2016; 60(1): 79-84. PubMed Abstract | Publisher Full Text

12. Moya-Salazar JJ, Rojas-Zumaran VA: Environmental Performance of xylene, hydrochloric acid and ammonia solution during Pap stain for diagnosing cervical cancer. J Health Pollution. 2016; 6(11): $58-65$. PubMed Abstract | Publisher Full Text | Free Full Text

13. Moya-Salazar J: Xylene data base used in EsSalud hospitals. Dataset. Figshare. 2021 Publisher Full Text

14. Moya-Salazar J: 2018 EsSalud Cytology Guideline - Chapter 9. Online resource. Figshare. 2021.

Publisher Full Text

15. Seguro Social de Salud (EsSalud): Resolución de gerencia central de prestaciones de salud n.04 - GCPS-ESSALUD-2018. Documento Técnico: Procedimiento de Citología cervical. Lima: EsSalud; 2018.

16. World Health Organization (WHO): International Programme on Chemical Safety: Environmental Health Criteria.Geneva: WHO; 1997.

17. Dergovics FL, Moura TP, Shirata NK, et al.: Avaliação do desempenho da mistura verniz/xilol na diafanização de lâminas de citopatologia coradas com a técnica de Papanicolaou. RBAC. 2012; 44(1): 35-38

18. Tiburtius ER, Peralta-Zamora $P$, Lea LE: Contaminação de águas por BTXs e procesos utilizados na remediação de sítios contaminados. Quím Nova. 2004; 27(3): 441-446.

19. Sandikci $M$, Seyrek $K$, Aksit $H$, et al.: Inhalation of formaldehyde and xylene induces apoptotic cell death in the lung tissue. Toxicol Ind Health. 2009; 25(7): 455-461. PubMed Abstract |Publisher Full Text

20. Occupational Safety and Health Administration (OSHA): U.S. Department of Health and Human Services, Public Health Services, Centers for Disease Control. Ocupational Health Guideline for Xylene. Georgia,Atlanta; 1978.

21. Moya-Salazar J, Pio DL: Prevalence of Cervical- Uterine Abnormalities associated with Poverty levels at "Hospital Nacional Docente Madre Niño San Bartolome" between 2011 . 2013. Rev Invest Universidad Norbert Wiener. 2014; 3(1): 89-99. PubMed Abstract | Publisher Full Text

22. Ramos-Ortega G, Díaz-Hernández MC, Rodríguez-Moctezuma JR, et al.: Satisfactory cervical cytologic smear against longitudina exocervical smears. Rev Med Inst Mex Seguro Soc. 2014; 52(6): 696-703. PubMed Abstract

23. Wheeler CM: Natural history of human papillomavirus infections, cytologic and histologic abnormalities, and cancer. Obstet Gynecol Clin North Am. 2008; 35(4): 519-536. PubMed Abstract | Publisher Full Text

24. Moya-Salazar J, Rojas-Zumaran V: Análisis de la problemática del xileno en los laboratorios Sudamericanos de citología. Rev Latinoam Patol Clin Med Lab. 2018; 65(3): 150-158.

25. Alwahaibi N, Aljaradi S, Alazri H: Alternative to xylene as a clearing agent in histopathology. J Lab Physicians. 2018; 10(2): 189-193.

PubMed Abstract | Publisher Full Text | Free Full Text

26. Kunhua W, Chuming F, Tao L, et al.: Novel Non-Toxic Xylene Substitute (SBO) for histology. Afr J Tradit Complement Altern Med. 2012; 9(1): 43-49.

PubMed Abstract | Publisher Full Text | Free Full Text

27. Buesa RJ, Peshkov MV: Histology without xylene. Ann Diag Pathol. 2009; 13(4): 246-256.

PubMed Abstract | Publisher Full Text

28. Harjes U: Pap seeking new challenges. Nat Rev Cancer. 2018; 18(6): 338-339.

PubMed Abstract | Publisher Full Text

29. Wright TC, Stoler MH, Behrens CM, et al.: Primary cervical cancer screening with human papillomavirus: end of study results from the ATHENA study using HPV as the first-line screening test. Gynecol Oncol. 2015; 136(2): 189-197. PubMed Abstract | Publisher Full Text

30. Alonso de Ruiz P, Lazcano Ponce EC, Hernández Ávila M: Cáncer cervicouterino. Diagnóstico, prevención y control. Medica Panamericana: Buenos Aires; 2000.

31. Moya-Salazar J, Rojas-Zumaran V: Tendencias en la investigación del Virus de Papiloma Humano en Latinoamérica y en los en los países de altos ingresos. Rev Colomb Obstet Ginecol. 2017; 68(3): 202-217.

32. Bray F, Ferlay J, Soerjomataram I, et al.: Global cancer statistics 2018: GLOBOCAN estimates of incidence and mortality worldwide for $\mathbf{3 6}$ cancers in $\mathbf{1 8 5}$ countries. CA Cancer Clin. 2018; 68(6): 394-424.

PubMed Abstract | Publisher Full Text 


\section{Open Peer Review}

\section{Current Peer Review Status: ? $\mathrm{X}$}

\section{Version 1}

Reviewer Report 22 February 2022

https://doi.org/10.5256/f1000research.56088.r122077

(c) 2022 Rieger A et al. This is an open access peer review report distributed under the terms of the Creative Commons Attribution License, which permits unrestricted use, distribution, and reproduction in any medium, provided the original work is properly cited.

\section{Alexandre Rieger}

Postgraduate Program in Health Promotion (PPGPS), University of Santa Cruz do Sul (UNISC), Santa Cruz do Sul, Brazil

\section{Alessandra Koehler}

Institute of Basic Health Sciences, Federal University of Rio Grande do Sul (UFRGS), Porto Alegre, Brazil

The manuscript brings a relevant theme, but I believe it is not suitable for indexing, according to the following comments:

What were the criteria for choosing the hospitals included in the study?

A very important information is missing. What are the reasons why the 2018 EsSalud cytology guidelines recommend using three baths of xylene? I didn't find this information. I believe this is important to mention, as clearly the addition of one more xylene bath increases costs and environmental impact. Therefore, there must be a coherent reason for this recommendation, which perhaps outweighs the harm of adding one more bath.

The cost analyzed should include factors other than the value of a liter of xylene, such as: time, need for skilled labor, possibility of automation, generation and disposal of waste.

Substitutes for the use of xylene are suggested. It is important, however, to compare the costs and also the quality of the results, in addition to illustrating them better. This would bring more impact to the conclusion, which unfortunately did not add many scientific gains, because, if only the cost and environmental impact are compared, certainly using three xylene baths instead of two will have more impact.

Is the work clearly and accurately presented and does it cite the current literature? No

Is the study design appropriate and is the work technically sound? 
No

Are sufficient details of methods and analysis provided to allow replication by others? Partly

If applicable, is the statistical analysis and its interpretation appropriate?

I cannot comment. A qualified statistician is required.

Are all the source data underlying the results available to ensure full reproducibility?

Yes

Are the conclusions drawn adequately supported by the results?

Yes

Competing Interests: No competing interests were disclosed.

Reviewer Expertise: Molecular biology; Genetics; Genotoxicity

We confirm that we have read this submission and believe that we have an appropriate level of expertise to state that we do not consider it to be of an acceptable scientific standard, for reasons outlined above.

Author Response 28 Mar 2022

Jeel Moya-Salazar, Universidad Norbert Wiener, Peru

Dear reviewer,

We welcome feedback. We made the following modifications in our study: What were the criteria for choosing the hospitals included in the study?

Response: We include the inclusion criteria in the methodology section.

Very important information is missing. What are the reasons why the 2018 EsSalud cytology guidelines recommend using three baths of xylene? I didn't find this information. I believe this is important to mention, as clearly the addition of one more xylene bath increases costs and environmental impact. Therefore, there must be a coherent reason for this recommendation, which perhaps outweighs the harm of adding one more bath.

Response: We have included this information in our methods. Basically, the purpose is to improve cytology procedures, without proposing an analysis of cost-

effectiveness or environmental impact of the use of xylene.

The cost analyzed should include factors other than the value of a liter of xylene, such as: time, need for skilled labor, possibility of automation, generation and disposal of waste. Substitutes for the use of xylene are suggested. It is important, however, to compare the costs and also the quality of the results, in addition to illustrating them better. This would bring more impact to the conclusion, which unfortunately did not add many scientific gains, because, if only the cost and environmental impact are compared, certainly using three xylene baths instead of two will have more impact. 
Response: We want to do a more structured analysis, but we don't have access to the data to include more variables. Therefore, we limit our study to a cost/liter analysis as a preliminary approximation to the topic. These features are added in the limitations section.

Sincerely,

Competing Interests: None

Reviewer Report 08 September 2021

https://doi.org/10.5256/f1000research.56088.r92919

(c) 2021 Alwahaibi N. This is an open access peer review report distributed under the terms of the Creative Commons Attribution License, which permits unrestricted use, distribution, and reproduction in any medium, provided the original work is properly cited.

\section{Nasar Yousuf Alwahaibi}

Allied Health Sciences Department, College of Medicine and Health Sciences, Sultan Qaboos University, Muscat, Oman

Although the study has academic merit, however, it lacks some important information: In the methodology, there are no inclusion and exclusion criteria for this retrospective study.

Xylene details are missing.

The manual staining for cervical cytology procedures in the laboratory (Section 9.5.1) is written in a different language but not in English. Please have a translation or a brief summary for the procedure.

Many low and middle-income countries recycle xylene and other chemical solutions used in histopathology to overcome the high cost of those solutions as well as to provide a pollution-prevention solution for the laboratory, the discussion section does not discuss this issue.

How do you get rid of xylene in Peru? Usually, the management of xylene is carried out by means of specific legislation created by the specific regulatory agency for this purpose.

Please justify the choice of only those four hospitals in Peru.

In Figure 2 and in all mentioned laboratories, there is no safety cabinet to cover the xylene containers, which is a concern for biomedical scientists working in the laboratory.

Please note that the title for the tables should be up, and the title for the figures should be 
underneath the figures.

Is the work clearly and accurately presented and does it cite the current literature? Partly

Is the study design appropriate and is the work technically sound?

Partly

Are sufficient details of methods and analysis provided to allow replication by others? Yes

If applicable, is the statistical analysis and its interpretation appropriate?

I cannot comment. A qualified statistician is required.

Are all the source data underlying the results available to ensure full reproducibility? Partly

Are the conclusions drawn adequately supported by the results?

Yes

Competing Interests: No competing interests were disclosed.

Reviewer Expertise: Histopathology

I confirm that I have read this submission and believe that I have an appropriate level of expertise to confirm that it is of an acceptable scientific standard, however I have significant reservations, as outlined above.

Author Response 28 Mar 2022

Jeel Moya-Salazar, Universidad Norbert Wiener, Peru

Dear Reviewer,

We welcome feedback. We have made modifications to the study on the following points: In the methodology, there are no inclusion and exclusion criteria for this retrospective study.

Response: Criteria of inclusion/exclusion have been included.

The manual staining for cervical cytology procedures in the laboratory (Section 9.5.1) is written in a different language but not in English. Please have a translation or a brief summary for the procedure.

Response: A short version of the procedure is included in reference 13. It's on Figshare

Many low and middle-income countries recycle xylene and other chemical solutions used in histopathology to overcome the high cost of those solutions as well as to provide a pollution-prevention solution for the laboratory, the discussion section does not discuss 
this issue.

Response: We added in the discussion.

How do you get rid of xylene in Peru? Usually, the management of xylene is carried out by means of specific legislation created by the specific regulatory agency for this purpose.

Response: We added in the discussion.

Please justify the choice of only those four hospitals in Peru.

Response: We selected four hospitals because they are the main ones of EsSalud and they were the ones that agreed to be part of the study.

In Figure 2 and in all mentioned laboratories, there is no safety cabinet to cover the xylene containers, which is a concern for biomedical scientists working in the laboratory.

Response: We agree with what you say, it is important to note that the four main hospitals in Lima do not yet have security booths. This is why, based on our research, we believe that adding one more xylene bath is not enough.

Please note that the title for the tables should be up, and the title for the figures should be underneath the figures

Response: It is an editorial issue that we already adjusted.

Sincerely

Competing Interests: None

The benefits of publishing with F1000Research:

- Your article is published within days, with no editorial bias

- You can publish traditional articles, null/negative results, case reports, data notes and more

- The peer review process is transparent and collaborative

- Your article is indexed in PubMed after passing peer review

- Dedicated customer support at every stage

For pre-submission enquiries, contact research@f1000.com 